\title{
Loop Transfer Recovery for the Grape Juice Concentration Process
}

\author{
Nelson Aros Oñate ${ }^{1}$ and Graciela Suarez Segali ${ }^{2}$ \\ ${ }^{1}$ Departamento de Ingeniería Eléctrica, Facultad de Ingeniería, \\ Universidad de La Frontera, Temuco, \\ 2Departamento de Ingeniería Química, Facultad de Ingeniería, \\ Universidad Nacional de San Juan, San Juan, \\ ${ }^{1}$ Chile \\ ${ }^{2}$ Argentina
}

\section{Introduction}

It is necessary to ensure the quality of concentrated, because it is highly used in the food industry in juices, drinks, sweets, etc. Its application is in full development because it can compete with any other constituent, it is a natural product, and considering that is a very important regional industry, marketing greatly affects the regional economy. Because of this, that it is extremely important to ensure quality and quantity concentrate.

Argentina is one of the principal producers and exporters of concentrated clear grape juices in the world. They are produced mainly in the provinces of San Juan and Mendoza (Argentine Republic) from virgin grape juice and in the major part from sulfited grape juices. The province of San Juan's legislation establishes that a portion of the grapes must be used for making concentrated clear grape juices. This product has reached a high level of penetration in the export market and constitutes an important and growing productive alternative.

An adequate manufacturing process, a correct design of the concentrate plants and an appropriate evaluation of their performance will facilitate optimization of the concentrated juices quality parameters. The plant efficiency is obtained from knowledge of the physics properties of the raw material and products. These properties are fundamental parameters that are used in the designing and calculations on all the equipment used and also in the control process.

The multi-step evaporation (M-SE) is the most important unit operation used in the food industry to concentrate juices of grapes and apples. Even when the main objective of this process is to produce a concentrated product, it should also possess certain organoleptic properties that are critical with respect to its quality and acceptance grade by the customers. Product requirements and the complex characteristics of the process such as non-linear behavior, input and output constraints, time delays and loop interactions justify the use of an advanced control system.

The rheological behavior influences directly the heat transfer coefficient (Pilati, 1998; Rubio, 1998) and therefore its knowledge is essential together with the influence of temperature on 
its value. The juices (concentrate and intermediate products) physical properties, such as density, viscosity, boiling point elevation, specific heat and coefficient of thermal expansion, are affected by their solid content and their temperature. For this reason, it is necessary to know the physical properties values, as a function of the temperature and the solids content, during the manufacture process.

The principal solids constituents of clear grape juices are sugars and its concentration affects directly the density, viscosity and refraction index. Tables were developed to relate reducing sugar contents, refractometric values and density of pure solutions, at $20^{\circ} \mathrm{C}$, for concentrate ranges from $0 \%$ to $85 \% \mathrm{w} / \mathrm{w}$ and sucrose solutions for different range concentrations $0 \%$ to $70 \%$ and a temperature range from 0 to $100^{\circ} \mathrm{C}$ (AOAC, 1995).

Barbieri (1980) worked with white concentrated clear grape juice in a falling film multiple effect evaporators. They obtained 18.2, 27.3, 38.6, 48.6 and $64.6^{\circ}$ Brix samples. They measured density, viscosity and boiling point elevation as a function of soluble solids concentration and temperature. They presented the results in plots with predictive equations for the properties which were studied.

Di Leo (1988) published density, refraction index and viscosity data for a rectified concentrated grape juice and an aqueous solution of a 1:1 glucose/levulose mixture, for a soluble solids concentrate range from 60 to $71 \%$ (in increments of $0.1 \%$ ) and $20^{\circ} \mathrm{C}$.

Pandolfi, (1991) studied physical and chemical characteristics of grape juices produced in Mendoza and San Juan provinces, Argentina. They determined density at $20^{\circ} \mathrm{C}$ in sulfited grape juices of $20-22^{\circ} \mathrm{Bx}$ and concentrated grape juices of $68-72{ }^{\circ} \mathrm{Bx}$. They obtained no information on intermediate concentrations or other temperatures.

In general, the clarified juice concentrates have a Newtonian behavior (Ibarz 1993; Rao 1984; Saenz, 1986; Saravacos, 1970), although some authors have found a small pseudoplasticity in the flow of grape concentrates, from the variety Concord (Vitis labrusca) for concentrations above $55^{\circ} \mathrm{Bx}$. It has been attributed to the presence of some soluble solids, mostly pectins and tartrates (Moressi, 1984; Saravacos, 1970). Other authors consider the juice concentrates as Newtonian, even at high soluble solids concentrations of $60-70^{\circ} \mathrm{Bx}$ (Barbieri, 1980; Di Leo, 1988; Rao, 1984; Schwartz, 1986).

If we analyze the temperature influence on this product's viscosity, it seems which is directly related with soluble solids concentration; the higher the concentration, the higher is the variation of the viscosity with temperature (Rao, 1984; Saravacos, 1970; Bayindirli, 1992; Crapiste, 1988; Constela, 1989).

Schwartz (1986) determined clear grape juice viscosity at 20, 30, 40 and $50^{\circ} \mathrm{C}$, for $30,40,50$, 60 and $66 \%$ soluble solids concentration, but did not publish the experimental data. These authors presented the correlation constants values of the Arrhenius equation for temperature, a potential and an exponential model between viscosity and solids concentration for each temperature studied.

The physical property that represents density change in a material, due to an increase in its temperature at constant pressure, is called the coefficient of thermal expansion. The importance of this parameter can be seen in the effect that density change in the product can have over heat transfer during the process. There is not publish data on the coefficient of the thermal expansion for grape juices and their concentrates. The existing information did not cover all the temperature and concentration ranges that are used in the evaporation process, or else cover to pure sugar solutions, or grape juices of other varieties and/ or originating in other geographical zones. 
On the other hand, sensitivity theory, originally developed by Bode (Bode, 1945), has regained considerable importance, due to the recent work developed by many researchers. This research effort has made evident the fundamental role played by sensitivity theory to highlight design tradeoffs and to analyze, qualitatively, control system performance. One of the fields of active research is the analysis of different design strategies from to point of view of sensibility properties. From this perspective one of the richest strategies is the optimal linear quadratic regulator (LQR). It is well known that the sensitivity of a LQR Loop is always less than one (Anderson, 1971). However, it is also known that when the state is not directly fed back but reconstructed through an observer this property is normally lost. In fact, the situation more general, since the recovery problem appears every time a control design based on state feedback design is implemented through observers.

It has been shown that when the plant is minimum-phase, a properly design Kalman filter provides complete recovery of the input sensitivity achieved by LQR will full state feedback (Doyle, 1979). Either full or partial-order filter may be used. On the other hand it is also known that it is generally impossible to obtain LTR if we use observers for a plant with unstable zeros. An exception to this rule arises in MIMO Systems when input directions are orthogonal to non-minimum phase zero directions (Zhang, 1990).

On the other hand, it is known that the only way to obtain full recovery for a general nonminimum-phase plant is to increase the number of independent measurements. This idea has been suggested in conjunction with the use of reduced-order Kalman filters (Friedland, 1989).

The additional independent measurements are used to modify the structure of the open loop transfer function. The standard LTR procedure is applied and it is the implemented combining the resulting full-order Kalman filter with the additional measurements optimally weighted. The idea is obviously to feed back only a subset of the state, for that reason we speak of 'partial' state feedback. The basic approach assumes that all states are available for measurement. However in this paper, it is also shown how to do $\boldsymbol{L}_{2}-$ optimization on the amount of recovery of the input sensitivity when a given set of measurements is available. This situation is important since in many additional situations there are limitations regarding which variables can be measured and how many additional sensors can be used. This connects the recovery theory with the issue of additional measurements raised in the context of practical ideas for control design, as illustrated in the control of the inverted pendulum; see (Middleton, 1990). The theory supporting the proposal is built on some import technical results which allow for computing the amount of recovery, as a function of frequency (Zhang, 1990).

\section{Process description}

Figure 1 show the input and output streams in a vertical generic effect evaporator with long tubes. The solution to be concentrated circulates inside the tubes, while the steam, used to heat the solution, circulates inside the shell around the tubes. The evaporator operates in parallel mode. The solution to be concentrated and the steam are fed to the first effect by the bottom and by the upper section of the shell, respectively. Later on, the concentrated solution from the first effect is pumped to the bottom of the second effect, and so on until the fourth effect. On the other hand, the vaporized solvent from each effect serve as heater in the next one. Each effect has a baffle in the upper section that serves as a drops splitter for the solution dragged by the vapor. The vapor from the fourth effect is sent to a condenser 
and leaves the process as a liquid. Finally, the solution leaving the fourth effect attains the desired concentration and the solution is sent to a storage tank.

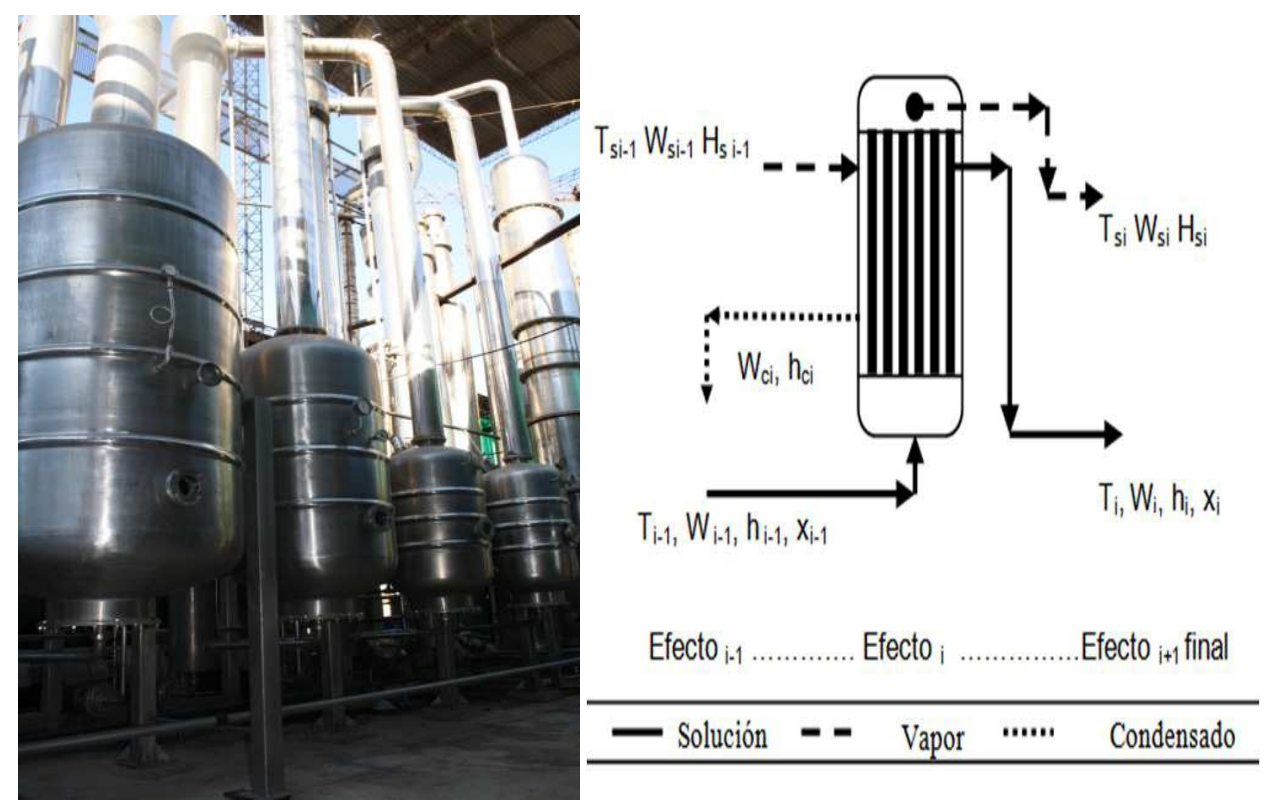

Fig. 1. Photo of evaporator and scheme of effect $\mathrm{i}$ in the four-stage evaporator flow sheet. $i=1, \cdots, 4$.

\section{Phenomenological model}

Stefanov (2005) has developed a rigorous model with distributed parameters based on partial differential equations for a falling-film evaporator, in which the open-loop stability of the model to disturbances is verified. On the other hand, various methods have been proposed in order to obtain reduced-order models to solve such problems (Armaou, 2002; Camacho, 1999; El-Farra, 2003; Zheng, 2002). However, there is not a general framework yet, which assure an effective implementation of a control strategy in a multiple effect evaporator.

In practice, due to a lack of measurements to characterize the distributed nature of the process and actuators to implement such a solution, the control of systems represented by PDE in the grape juice evaporator, is carried out neglecting the spatial variation of parameters and applying lumped systems methods. However, a distributed parameters model must be developed in order to be used as a real plant to test advance control strategies by simulation.

The mathematical model of the evaporator is obtained by application of the mass and energy balances to each effect:

a. Global mass balances in each effect:

$$
\frac{d M_{i}}{d t}=W_{i-1}-W_{s i}-W_{i}
$$


in this equations $W_{i}, i=1, \cdots, 4$, are the solution mass flow rates leaving the effects 1 to 4 , respectively. $W_{0}$ is the input mass flow rate that is fed to the equipment. $W_{s i}, i=1, \cdots, 4$, are the vapor mass flow rates coming from effects 1 to 4 , respectively. $d M_{i} / d t, i=1, \cdots, 4$, represent the solution mass variation with the time for each effect.

b. Solute mass balances for each effect:

$$
\frac{d\left(M_{i} X_{i}\right)}{d t}=W_{i-1} X_{i-1}-W_{i} X_{i}
$$

where, $X_{i}, i=1, \cdots, 4$, are the concentrations of the solutions that leave the effects 1 to 4 , respectively. $X_{0}$ is the concentration of the fed solution.

c. Energy balances:

$$
\frac{d\left(M_{i} h_{i}\right)}{d t}=W_{i-1} h_{i-1}-W_{i} h_{i}-W_{s i} H_{s i}+A_{i} U_{i}\left(T_{s i-1}-T_{i}\right)
$$

where, $h_{i}, i=1, \cdots, 4$, are the liquid stream enthalpies that leave the corresponding effects, $h_{0}$ is the feed solution enthalpy, and $H_{s i}, i=1, \cdots, 4$, are the vapor stream enthalpies that leave the corresponding effects and, $A_{i}$ represents the heat transfer area in each effect. The model also includes algebraic equations. The vapor flow rates for each effect are calculated neglecting the following terms: energy accumulation and the heat conduction across the tubes. Therefore:

$$
W_{s i}=\frac{U_{i} A_{i}\left(T_{s i-1}-T_{i}\right)}{H_{s i-1}-h_{c i}}
$$

For each effect, the enthalpy can be estimated as a function of temperatures and concentrations (Perry, 1997), where:

$$
\begin{gathered}
H_{s i}=2509.2888+1.6747 \cdot T_{s i} \\
h_{c i}=4.1868 \cdot T_{s i} \\
C_{\rho i}=0.80839-4.3416 \cdot 10^{-3} \cdot X_{i}+5.6063 \cdot 10^{-4} \cdot T_{i} \\
h_{i}=0.80839 \cdot T_{i}-4.3416 \cdot 10^{-3} \cdot X_{i} T_{i}+2.80315 \cdot 10^{-4} \cdot T_{i}^{2}
\end{gathered}
$$

$T_{i}, i=1, \cdots, 4$, are the solution temperatures in each effect, and $T_{s 0}$ is the vapor temperature that enters to the first effect. $T_{s i}, i=1, \cdots, 4$, are the vapor temperatures that leave each effect. The heat transfer coefficients are:

$$
U_{i}=\frac{490 \cdot\left(D^{0.57} \cdot W_{s i}^{3.6 / L}\right)}{\mu_{i}^{0.25} \cdot \Delta T_{i}^{0.1}}
$$

where, the Arrhenius type equation for the viscosity is:

$$
\begin{gathered}
\mu_{i}=\mu_{0} \cdot e^{\frac{A \cdot X_{i}}{100-B \cdot X_{i}}} \\
A=C_{1}+\frac{C_{2}}{T_{i}} \\
B=C_{3}+C_{4} \cdot T_{i}
\end{gathered}
$$


The global heat-transfer coefficients are directly influenced by the viscosity and indirectly by the temperature and concentration in each effect. The constants $C_{1}, C_{2}, C_{3}, C_{4}$ depend on the type of product to be concentrated (Kaya, 2002).

Although the model could be improved, the accuracy achieved is enough to incorporate a control structure.

\section{Standard LTR procedure}

\subsection{The basic approach}

Consider a linear time-invariant system with state characterization is given by:

$$
\begin{gathered}
\dot{x}=A x(t)+B u(t)+v(t) \\
y(t)=C x(t)
\end{gathered}
$$

where $\boldsymbol{x}(\boldsymbol{t}) \in \boldsymbol{R}^{\boldsymbol{n}}, \boldsymbol{u}(\boldsymbol{t}) \in \boldsymbol{R}^{\boldsymbol{m}}, \mathbf{v}(\boldsymbol{t}) \in \boldsymbol{R}^{\boldsymbol{m}}, \boldsymbol{y}(\boldsymbol{t}) \in \boldsymbol{R}^{\boldsymbol{l}}, \mathbf{A}, \mathbf{B}$ and $\boldsymbol{C}$ have consistent dimensions. We further assume that is a wide sense stationary process with covariance matrix $\boldsymbol{Q}$.

We then have that the system transfer matrix function is given by:

$$
G(s)=C(s I-A)^{-1} B
$$

If the state feedback law:

$$
\boldsymbol{u}(\boldsymbol{t})=-\boldsymbol{F} \boldsymbol{x}(\boldsymbol{t})
$$

is applied, we obtain an input sensitivity function is given by:

$$
S_{0}(s)=|I+H(s)|^{-1}
$$

where:

$$
H(s)=F(s I-A)^{-1} B
$$

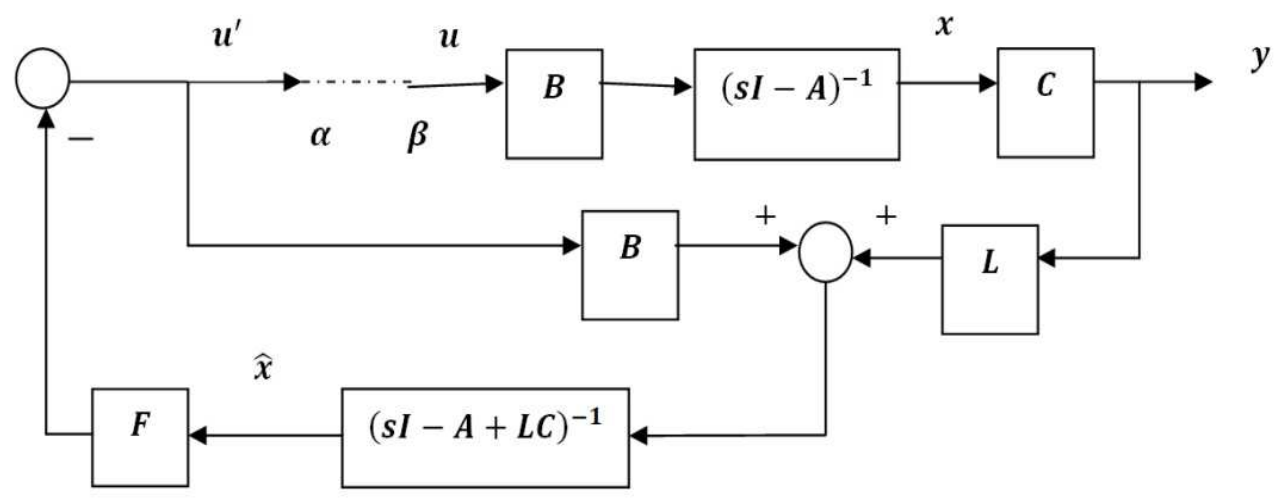

Fig. 2. Optimal LQG Scheme

The complete LQG control system appears in figure 2. The question of loop transfer recovery deals with the problem of keeping the sensitivity given in equation (17) when the 
control law is implemented with an observer of the state (Stein, 1987), i.e. the control $\boldsymbol{u}(\boldsymbol{t})$ is generated trough:

$$
\boldsymbol{u}(\boldsymbol{t})=-\boldsymbol{F} \widehat{\boldsymbol{x}}(\boldsymbol{t})
$$

where $\hat{x}(\boldsymbol{t})$ is the output of a state observer is given by:

$$
\dot{\hat{x}}(t)=A \widehat{x}(t)+B u(t)+L\{y(t)-C \widehat{x}(t)\}
$$

If the observer is designed using standard Kalman filter theory, then the filter gain $\boldsymbol{L}$ satisfies:

$$
L=\sum C^{T}
$$

where $\sum$ is the symmetric nonnegative definite solution of the algebraic Riccati equation:

$$
A \sum+\sum A^{T}-\sum C^{T} C \sum+Q=0
$$

In this case the input sensitivity is given by:

$$
S_{o b s}(s)=\left\{I+\left[I+F(s I-A+L C)^{-1} B\right]^{-1} F(s I-A+L C)^{-1} L C(s I-A)^{-1} B\right\}^{-1}
$$

After some elementary matrix manipulation, we obtain:

$$
S_{o b s}(s)=S_{o}(s)\left\{I+F(s I-A+L C)^{-1} B\right\}
$$

Or

$$
S_{o b s}(s)=S_{o}(s)\left\{I+F \phi\left[B-L(s I-A+L C)^{-1} C \phi B\right]\right\}
$$

where:

$$
\phi=(s I-A)^{-1}
$$

It becomes then sensible to measure the amount of recovery by the relative sensitivity error (Turan, 1990) given by:

$$
E(s)=S_{o}^{-1}\left\{S_{o b s}-S_{o}\right\}
$$

Using the equation (25) we obtain:

$$
E(s)=F(s I-A+L C)^{-1} B
$$

It has been shown (Doyle, 1979) that if $\boldsymbol{G}(\boldsymbol{s})$ is a minimum-phase transfer matrix then complete recovery, i.e. $\boldsymbol{E}(\boldsymbol{s})=\mathbf{0}$, can be achieved provided that:

- We first augment equation (13) to read:

$$
\dot{x}=\boldsymbol{A x}(\boldsymbol{t})+\boldsymbol{B}\{\boldsymbol{u}(\boldsymbol{t})+\boldsymbol{U w}(\boldsymbol{t})\}+\boldsymbol{v}(\boldsymbol{t})
$$

where $\boldsymbol{w}(\boldsymbol{t}) \in \boldsymbol{R}^{\boldsymbol{m}}$ is a wide sense stationary process with covariance matrix $\boldsymbol{q}^{2} \boldsymbol{I}$ and $\boldsymbol{U}$ is a unitary matrix. We assume that $\boldsymbol{v}(\boldsymbol{t})$ and $\boldsymbol{w}(\boldsymbol{t})$ are uncorrelated.

- We then solve the Riccati equation (10) substituting $\mathrm{Q}$ by $\mathrm{Q}+\mathrm{qBB}^{\mathrm{T}}$

- We finally let $\boldsymbol{q} \rightarrow \infty$. In this case $\boldsymbol{L}(\boldsymbol{q}) \rightarrow \boldsymbol{q} \boldsymbol{B} \boldsymbol{U}$.

The above procedure yields:

$$
S_{o b s}(s) \rightarrow S_{o}(s)
$$




\subsection{A factorized form of non-minimum phase plants}

It is known that a transfer matrix function $\boldsymbol{G}(\boldsymbol{s})$ with zeros in $\boldsymbol{C}^{+}$(right-half complex plane) can be described as:

$$
\boldsymbol{G}(\boldsymbol{s})=\boldsymbol{G}_{\boldsymbol{m}}(\boldsymbol{s}) \boldsymbol{B}_{\mathbf{z}}(\boldsymbol{s})
$$

where $\boldsymbol{B}_{\boldsymbol{Z}}(\boldsymbol{s})$ is a stable all-pass factor with zeros located at the non-minimum-phase zeros of $\boldsymbol{G}(\boldsymbol{s})$ and satisfies $\boldsymbol{B}_{\mathbf{z}}(\boldsymbol{s}) \boldsymbol{B}_{\mathbf{Z}}^{T}(\boldsymbol{s})=\boldsymbol{I}$.

One possible way to build the factorization of equation (31) has been proposed by Enns (Enns, 1984; Zhang, 1990). The main result can be stated as follows.

Lemma 2.1 Given a transfer matrix function $\boldsymbol{G}(\boldsymbol{s})=\boldsymbol{C}(\boldsymbol{s} \boldsymbol{I}-\boldsymbol{A})^{\mathbf{- 1}} \boldsymbol{B}$ with $\boldsymbol{l} \in \boldsymbol{C}^{+}$zeros (including multiplicity), $z_{1}, \cdots, z_{l}$, there exists a matrix $\boldsymbol{B}_{\boldsymbol{m}}$ such that:

$$
G(s)=C(s I-A)^{-1} B_{m} B_{z}(s)
$$

where $\boldsymbol{G}(\boldsymbol{s})=\boldsymbol{C}(\boldsymbol{s} \boldsymbol{I}-\boldsymbol{A})^{-\mathbf{1}} \boldsymbol{B}_{\boldsymbol{m}}$ is minimum-phase and $\boldsymbol{B}_{\boldsymbol{z}}(\boldsymbol{s})$ is an all-pass stable matrix factor. We then have that:

$$
B_{z}(s)=B_{z_{1}}(s) B_{z_{2}}(s) \cdots B_{z_{l}}(s)
$$

and

$$
B_{m}=B_{m}^{l}
$$

where, for $i=1, \cdots, l$ :

$$
B_{z_{i}}(s)=I-\frac{2 \Re e\left\{z_{i}\right\}}{s+z_{i}^{*}} \eta_{i} \eta_{i}^{H}
$$

and

$$
B_{m}^{i}=B_{m}^{i-1}-2 \Re e\left\{z_{i}\right\} \xi_{i} \eta_{i}^{H}
$$

with $B_{m}^{0}=B, G_{m}^{i}(s):=C(s I-A)^{-1} B_{m}^{i}$.

The symbol $\mathfrak{R} \boldsymbol{e}\{$.$\} denotes the real part operator. The vectors \boldsymbol{\eta}_{\boldsymbol{i}}$ and $\boldsymbol{\xi}_{\boldsymbol{i}}$ are solutions of:

$$
\left[\begin{array}{cc}
z_{i} I-A & -B_{m}^{i-1} \\
-C & 0
\end{array}\right]\left[\begin{array}{l}
\xi_{i} \\
\eta_{i}
\end{array}\right]=0
$$

We also have the following useful results:

Lemma 2.2 For SISO systems, the sequence $\left\{B_{m}^{k}\right\}$ can be alternatively computer as:

$$
B_{m}^{k}=\underbrace{\prod_{i=1}^{k}\left\{I-2 \Re e\left(z_{i}\right)\left(z_{i} I-A\right)^{-1}\right\}}_{\equiv M_{k}} B
$$

Proof:

$$
\begin{aligned}
& \text { A1.- } \boldsymbol{B}_{\boldsymbol{m}}^{\mathbf{0}}=\boldsymbol{B} \\
& \text { A2.- From (36) } \boldsymbol{B}_{\boldsymbol{m}}^{\mathbf{1}}=\boldsymbol{B}_{\boldsymbol{m}}^{\mathbf{0}}-\mathbf{2} \boldsymbol{R e}\left\{\mathbf{z}_{\mathbf{1}}\right\} \xi_{\mathbf{1}} \boldsymbol{\eta}_{\mathbf{1}}^{\boldsymbol{H}} \text {. } \\
& \text { But for SISO systems } \boldsymbol{\eta}_{\mathbf{1}}=\boldsymbol{\eta}_{\mathbf{2}}=\cdots=\mathbf{1} \\
& \text { and from (37) } \xi_{\mathbf{1}}=\left(\mathbf{z}_{\mathbf{1}} \boldsymbol{I}-\boldsymbol{A}\right)^{-\mathbf{1}} \boldsymbol{B}_{\boldsymbol{m}}^{\mathbf{0}} \\
& \text { therefore } \boldsymbol{B}_{\boldsymbol{m}}^{\mathbf{1}}=\underbrace{\left\{\boldsymbol{I}-\mathbf{2} \boldsymbol{R e}\left(\mathbf{z}_{\mathbf{1}}\right)\left(\mathbf{z}_{\mathbf{1}} \boldsymbol{I}-\boldsymbol{A}\right)^{-\mathbf{1}}\right\}}_{\equiv \boldsymbol{M}_{\mathbf{1}}} \boldsymbol{B}
\end{aligned}
$$


A3.- From (36) $\boldsymbol{B}_{\boldsymbol{m}}^{\boldsymbol{k}}=\boldsymbol{B}_{\boldsymbol{m}}^{\boldsymbol{k} \mathbf{1}}-\mathbf{2} \boldsymbol{R} \boldsymbol{e}\left\{\mathbf{z}_{\boldsymbol{k}}\right\} \boldsymbol{\xi}_{\boldsymbol{k}}$. But for SISO systems $\boldsymbol{\eta}_{\boldsymbol{k}}=\mathbf{1}$, and from (37) we have that $\boldsymbol{B}_{\boldsymbol{m}}^{\boldsymbol{k}}=\left\{\boldsymbol{I}-\mathbf{2} \boldsymbol{R} \boldsymbol{e}\left(\mathbf{z}_{\boldsymbol{k}}\right)\left(\mathbf{z}_{\boldsymbol{k}} \boldsymbol{I}-\boldsymbol{A}\right)^{-\mathbf{1}}\right\} \boldsymbol{B}_{\boldsymbol{m}}^{\boldsymbol{k}-\mathbf{1}}$

then if (37) is satisfied for $k-1$, the result follows.

Corollary:

$$
\begin{gathered}
\xi_{k}=\left(z_{k} I-A\right)^{-1} M_{k-1} B \\
M_{0}=I \\
M_{1}=I-2 \Re e\left(z_{1}\right)\left(z_{1} I-A\right)^{-1}
\end{gathered}
$$

Theorem 2.1 Consider a non-minimum-phase system $(\boldsymbol{A}, \boldsymbol{B}, \boldsymbol{C})$, and its minimum-phase counterpart $\left(\boldsymbol{A}, \boldsymbol{B}_{m}, \boldsymbol{C}\right)$, with $\boldsymbol{B}_{\boldsymbol{m}}$ computed according to lemma 2.1. Let $\boldsymbol{L}$ and $\boldsymbol{L}_{\boldsymbol{m}}$ be the optimal observer gains for these two systems, then $\boldsymbol{L}_{\boldsymbol{m}}=\boldsymbol{L}$.

Proof: See Zhang \& Freudenberg (Zhang, 1990).

\subsection{Loop transfer recovery and non-minimum phase plants}

Assume now that $\boldsymbol{G}(\boldsymbol{s})$ is a non-minimum phase plant and that it is factorized as in equation (33). If the standard LTR procedure is applied to recover the input sensitivity, then when $\boldsymbol{q} \rightarrow \infty$ the sensitivity function satisfies:

$$
S_{o b s}(s)=S_{o}(s)\{I+E(s)\}
$$

where

$$
E(s):=F(s I-A)^{-1}\left\{B-q B_{m} W\left(I+q C \phi B_{m} W\right)^{-1} C \phi B_{m} B_{z}(s)\right\}
$$

then

$$
E(s)=F(s I-A)^{-1}\left\{B-B_{m} B_{z}(s)\right\}
$$

It has been also shown that:

$$
E(s)=E^{i}(s)=\sum_{k=1}^{l} \frac{2 \Re e\left\{z_{k}\right\}}{s+z_{k}^{*}} F \xi_{k} \eta_{k}^{H} B_{z}^{k-1}(s)
$$

From equation (44) it is evident that for this type of plants the amount of recovery at a frequency $w$ depends on the value of $\|\boldsymbol{E}(\boldsymbol{j w})\|$, where $\|$.$\| is a suitable norm. As in equation$ (41), $\boldsymbol{E}(\boldsymbol{s})$ corresponds to the error of the sensitivity in loop with the LTR observer.

The results of the previous two sections can be appreciated if we consider a SISO system with one zero in $\boldsymbol{s}=\boldsymbol{z} \in \boldsymbol{R}^{+}$. If the standard LTR procedure is applied we have that:

$$
\lim _{q \rightarrow s s} S_{o b s}(s)=S_{o}(s)\left\{1+\frac{2 z}{s+z} H(z)\right\}
$$

where

$$
H(z)=F(z I-A)^{-1} B
$$

One can then notice that if $|\boldsymbol{H}(\mathbf{z})|$ is small, i.e. when the LQR design bandwidth is small in comparison with the magnitude of the $\boldsymbol{C}^{+}$zero, then the recovery is almost complete. This 
case will be also the situation for high frequencies since the factor $\frac{2 z}{s+z}$ is low-pass filter. The sensitivity resulting from a LQR/LTR applied to a non-minimum phase plant is very significant at low frequencies and decreases as the frequency increases. The inability of the LQR/LTR scheme to recover sensitivity is consistent with some fundamental design tradeoffs for non-minimum phase systems (Freudenberg, 1988).

\subsection{LTR procedure with partial state feedback (LTR/PSF)}

If we assume that, apart from the system output, there is one or more independent measurements, we can implement a control system originally designed to work with state with state feedback via a mixture of observed and measured states (Aros, 1991). We propose to use the scheme shown in figure 3, where $\boldsymbol{\Gamma}$ is a diagonal matrix with nonzero diagonal entries for the corresponding measures states. It then becomes clear that $\boldsymbol{\Gamma}=\mathbf{0}$ corresponds to the standard LTR scheme and $\boldsymbol{\Gamma}=\boldsymbol{I}$ corresponds to the optimal regulator with full state feedback.

A key result to describe the degree of recovery in the non-minimum phase case is given in the next lemma.

Lemma 3.1 Assume that the plant $\boldsymbol{G}(\boldsymbol{s})=\boldsymbol{C}(\boldsymbol{s} \boldsymbol{I}-\boldsymbol{A})^{-\mathbf{1}} \boldsymbol{B}$ in non-minimum phase with $\boldsymbol{l} \in \boldsymbol{C}^{+}$ zeros and factorized according to lemma 2.1. Then if we use a LTR/PSF scheme and we let $\boldsymbol{q} \rightarrow \infty$ the sensitivity function is given by:

$$
S_{\Gamma}(s)=S_{o}(s)\left\{I+\sum_{k=1}^{l} F(I-\Gamma) \xi_{k} \eta_{k}^{H} W_{k}(s)\right\}
$$

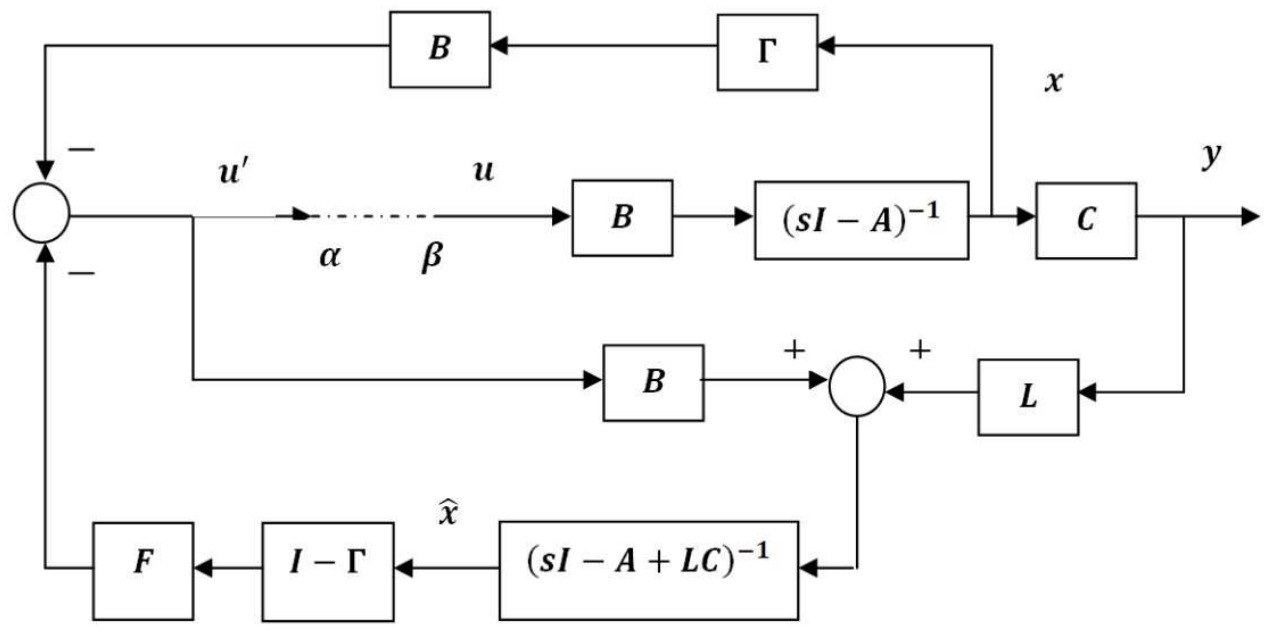

Fig. 3. LTR/PSF scheme.

where:

$$
\begin{gathered}
W_{k}(s)=\frac{2 \Re e\left(z_{k}\right)}{s+z_{k}^{*}} B_{z}^{k-1}(s) \\
B_{z}^{k-1}(s)=\prod_{i=1}^{k} B_{z_{i}}(s)
\end{gathered}
$$




$$
B_{z_{i}}(s)=\frac{-s+z_{i}}{s+z_{i}^{*}}
$$

Proof: Straightforward on using lemma 2.1 and equation (45).

Remark 3.1 For SISO systems $\boldsymbol{\eta}_{\boldsymbol{k}}=\mathbf{1} \forall \boldsymbol{k}$ and consequently (53) simplifies to:

$$
S_{\Gamma}(s)=S_{o}(s)\left\{I+\sum_{k=1}^{l} F(I-\Gamma) \xi_{k} W_{k}(s)\right\}
$$

Sufficient and necessary conditions for full recovery in SISO systems are given in the next theorem:

Theorem 3.1 Assume that a plant with transfer function $\boldsymbol{G}(\boldsymbol{s})$ has $\boldsymbol{l} \in \boldsymbol{C}^{+}$zeros denoted by $z_{1}, \cdots, z_{l}$. We apply the LTR/PSF procedure we obtain $\boldsymbol{E}_{\boldsymbol{\Gamma}}(\boldsymbol{s})=\mathbf{0}$, if $\boldsymbol{F}(\boldsymbol{I}-\boldsymbol{\Gamma})$ is orthogonal to $\xi_{k}$ for $\boldsymbol{k}=1,2, \cdots, l$ when $\boldsymbol{q} \rightarrow \infty$.

Proof:

i. Sufficiency: straightforward on inspection of equation (53).

ii. Necessity: consider equation (57). We first notice that given the fact that functions $W_{k}(s)$ form a set of linearly independent functions, the only way to nullify the sum $\forall s$ is that the scalar $\boldsymbol{F}(\boldsymbol{I}-\boldsymbol{\Gamma}) \xi_{\boldsymbol{k}}$ be made equal to zero $\forall k$.

The user must then choose (if possible) the matrix $\boldsymbol{\Gamma}$ to satisfy the orthogonality condition in theorem 3.1. Equivalently, $\boldsymbol{\Gamma}$ must satisfy:

$$
F T \zeta_{k}=F \xi_{k} \quad k=1,2, \cdots, l
$$

The computation of $\boldsymbol{\Gamma}$ is given the next lemma.

Lemma 3.2 Consider a SISO plant as in theorem 3.1. If the LTR/PSF scheme is applied measuring, apart from the output, states $\boldsymbol{x}_{1}, \boldsymbol{x}_{\mathbf{2}} \cdots, \boldsymbol{x}_{\boldsymbol{\lambda}}$ then we obtain full recovery of the sensitivity if there exist $\boldsymbol{\gamma}_{\mathbf{1}}, \boldsymbol{\gamma}_{\mathbf{2}} \cdots, \boldsymbol{\gamma}_{\lambda}$, with $\boldsymbol{\Gamma}=\operatorname{diag}\left\{\gamma_{1}, \gamma_{2}, \cdots, \gamma_{\lambda}, 0, \cdots, 0\right\}$, satisfying:

$$
\left[\begin{array}{ccc}
\alpha_{1_{1}} & \cdots & \alpha_{\lambda_{1}} \\
\vdots & \ddots & \vdots \\
\alpha_{1_{l}} & \cdots & \alpha_{\lambda_{l}}
\end{array}\right]\left[\begin{array}{c}
\gamma_{1} \\
\vdots \\
\gamma_{\lambda}
\end{array}\right]=\left[\begin{array}{c}
\sum_{i=1}^{n} \alpha_{i_{1}} \\
\vdots \\
\sum_{i=1}^{n} \alpha_{i_{l}}
\end{array}\right]
$$

where

$$
\begin{gathered}
\alpha_{i_{k}}=f_{i} \xi_{k_{i}} ; \quad i=1,2, \cdots, n \\
F=\left[\begin{array}{llll}
\boldsymbol{f}_{1} & \boldsymbol{f}_{2} & \cdots & \boldsymbol{f}_{\boldsymbol{n}}
\end{array}\right] \\
\xi_{\boldsymbol{\kappa}}=\left[\begin{array}{llll}
\xi_{\boldsymbol{k}_{1}} & \xi_{k_{2}} & \cdots & \xi_{k_{n}}
\end{array}\right]^{T}
\end{gathered}
$$

Proof: By straight substitution.

Remark 3.2 From equation (53) it appears that full recovery is obtained $\forall \boldsymbol{\Gamma}$ if $\boldsymbol{\eta}_{\boldsymbol{k}}$ and $\boldsymbol{\xi}_{\boldsymbol{k}}$ are orthogonal. This it shows that the LTR/PSF scheme maintains the standard LTR property claimed in Wall (Wall, 1980) and proved in Zhang (Zhang, 1990).

Remark 3.3 A complete analysis of the conditions the existence of none, one or an infinite number of solutions is out of the scope of this work, but some insight can be gained on analyzing the one RHP zero case and $\boldsymbol{L}_{2}$ optimization. Both topics will be addressed below. 
Theorem 3.2 Consider a scalar plant with transfer function $\boldsymbol{G}(\boldsymbol{s})$ and one RHP zero located at $s=z$. If the LTR/PSF is applied measuring the input and one additional state variable (not proportional to the output) then $\boldsymbol{S}_{\Gamma}(\boldsymbol{s}) \rightarrow \boldsymbol{S}_{\boldsymbol{o}}(\boldsymbol{s})$ when $\boldsymbol{q} \rightarrow \infty$.

Proof:

From (50) and (46), we can write:

$$
\lim _{q \rightarrow s s} S_{\Gamma}(s)=S_{o}(s)\left\{1+\frac{2 z}{s+z^{*}} H(z)-\frac{2 z}{s+z^{*}} H^{\prime}(z)\right\}
$$

where $\boldsymbol{H}(\boldsymbol{s})$ is given in equation (47) and

$$
H^{\prime}(z)=F \Gamma(z I-A)^{-1} B
$$

Without loss of generality we can assume that the state variable being fed back is $\boldsymbol{x}_{\mathbf{1}}(\boldsymbol{t})$. We can thus express $\boldsymbol{\Gamma}$ as:

$$
\Gamma=\gamma \Gamma^{\prime}
$$

where

$$
\Gamma^{\prime}=\operatorname{diag}\{1,0, \cdots, 0\}
$$

then full recovery is obtained if $\boldsymbol{\gamma}$ is chosen to satisfy:

$$
\gamma==\frac{\mathbf{F}(\mathbf{z I}-\mathbf{A})^{-1} \mathbf{B}}{\mathbf{F}^{\prime}(\mathbf{z I}-\mathbf{A})^{-1} \mathbf{B}}
$$

Remark 3.4 On examining equation (67) we note:

1. If the output is proportional to $\boldsymbol{x}_{\mathbf{1}}$ there is not solution for $\boldsymbol{\gamma}$ since then $\mathbf{F} \boldsymbol{\Gamma}^{\prime}(\mathbf{z I}-$ $\boldsymbol{A})^{-\mathbf{1}} \boldsymbol{B}=\mathbf{0}$. It certainly agrees with intuition, since nothing can be gained by measuring twice the same variable.

2. There is not solution either when $\mathbf{F} \boldsymbol{\Gamma}^{\prime}=\mathbf{0}$. This case also is intuitive since this situation corresponds to a control law where $\boldsymbol{x}_{\mathbf{1}}(\boldsymbol{t})$ was not required to be fed back.

These results also apply, mutatis mutandis, to MIMO systems, with the additional complexity which comes from the directionality properties of multivariable systems.

\section{$L_{2}$ Optimization}

When the designer don't have freedom to choose which state variable can be measured, due either to technical or economical reasons, then the feedback gains for the additional available measurements can be computed by solving an optimization problem. The simplest optimization problem can be posed in $\boldsymbol{L}_{2}$. We examine that case for SISO systems.

Assume first that we measure and feed back the state variables $\boldsymbol{x}_{\mathbf{1}}(\boldsymbol{t}), \boldsymbol{x}_{\mathbf{2}}(\boldsymbol{t}), \cdots, \boldsymbol{x}_{\lambda}(\boldsymbol{t})$ with gains $\left[\gamma_{1}, \gamma_{2} \cdots, \gamma_{\lambda}\right]^{T}$. Then the $\boldsymbol{L}_{2}$ optimization problem consists in finding a vector $\boldsymbol{\gamma}^{\boldsymbol{o}}$ satisfying:

$$
\gamma^{\mathbf{o}}=\arg \min _{\gamma \in \Re \mathrm{e}^{\lambda}} \mathrm{J}(\boldsymbol{\gamma})
$$

where

$$
\begin{gathered}
J=\int_{0}^{\infty}\left|E_{\Gamma}(j w)\right|^{2} d w \\
J=\int_{0}^{\infty}\left\|G_{1}(j w)+\gamma^{T} G_{2}(j w)\right\|^{2} d w
\end{gathered}
$$


with

$$
\begin{gathered}
G_{1}(j w)=F(j w I-A+L C)^{-1} B \\
\gamma^{T} G_{2}(j w)=F \Gamma(j w I-A+L C)^{-1} B
\end{gathered}
$$

This problem has a unique solution if $\boldsymbol{G}(\boldsymbol{j w})$ is not identical to zero. This unique solution is given by:

$$
\gamma^{\mathbf{0}}=-\left[\int_{0}^{\infty} \mathbf{G}_{2}(\mathbf{j w})\left[\mathbf{G}_{2}^{*}(\mathbf{j w})\right]^{\mathrm{T}} \mathbf{d w}\right]^{-1} \mathfrak{R e}\left\{\int_{0}^{\infty} \mathbf{G}_{1}(\mathbf{j w}) \mathbf{G}_{2}^{*}(\mathbf{j w}) \mathbf{d w}\right\}
$$

for $\lambda=1$ equation (73) becomes:

$$
\gamma^{\mathbf{0}}=-\frac{\Re \mathbf{R}\left\{\int_{0}^{\infty} \mathbf{G}_{1}(\mathbf{j w}) \mathbf{G}_{2}^{*}(\mathbf{j w}) \mathbf{d w}\right\}}{\int_{0}^{\infty}\left\|\mathbf{G}_{2}(\mathbf{j w})\right\|^{2} \mathbf{d w}}
$$

\section{Simulatinos results}

\subsection{Open loop}

In figure 4, it shows the response of open loop system, when making a disturbance in one of the manipulated variables such as power flow; it represents the temperature of the first effect and concentration effect of the fourth output.

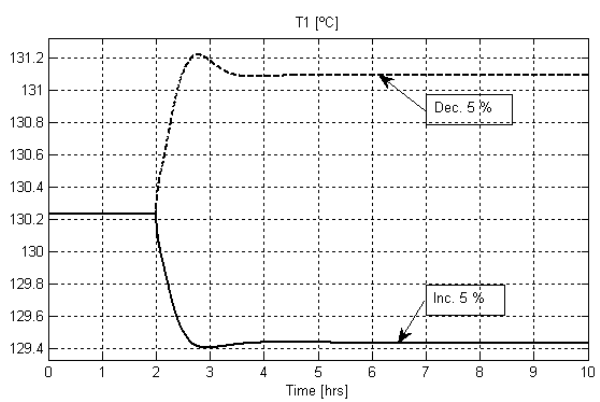

(a)

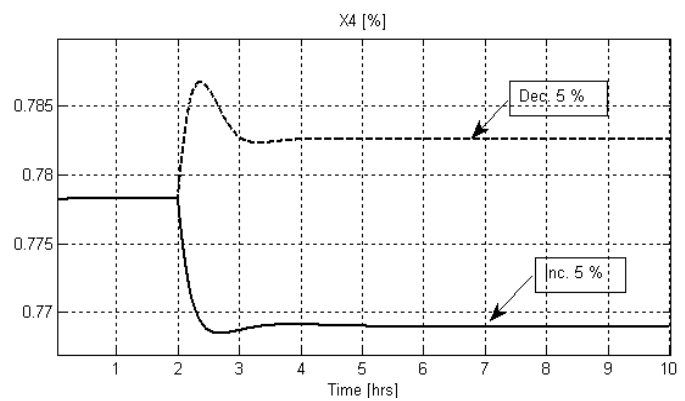

(b)

Fig. 4. Behavior of the concentration in the evaporator to a change of a step in the flow of food (up 5\% - decrease of 5\%)

In figure 5, it shows the response of open loop system, when making a disturbance in the steam temperature is the other manipulated variable; it represents the temperature of the first effect and concentration effect of the fourth output.

In figure 6, it shows the response of open loop system, when performing a step in one of the shocks as the concentration of power; it represents the temperature of the first effect and concentration effect of the fourth output.

In Figure 7, it shows the response of open loop system, when performing a step in the temperature of the food which is the other perturbations of the system; it represents the temperature of the first effect and concentration effect of the fourth output. 


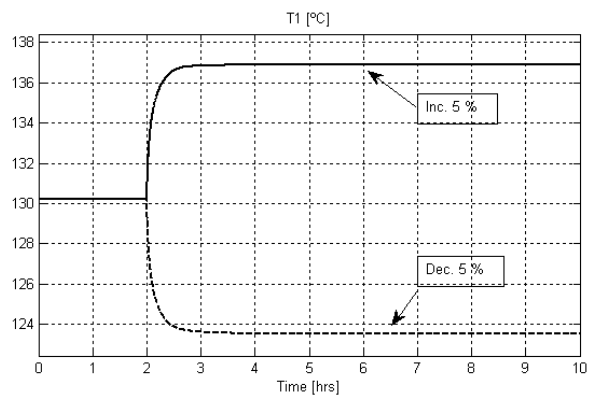

(a)

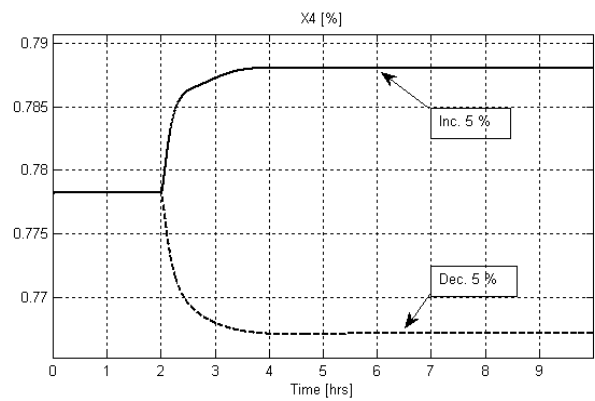

(b)

Fig. 5. Behavior of the concentration in the evaporator to a change of a step in the temperature of steam power (up 5\% - decrease of 5\%)

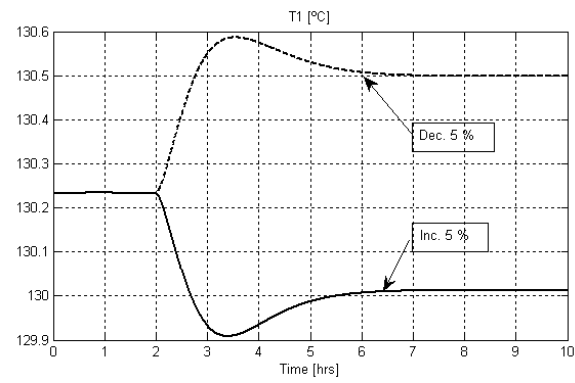

(a)

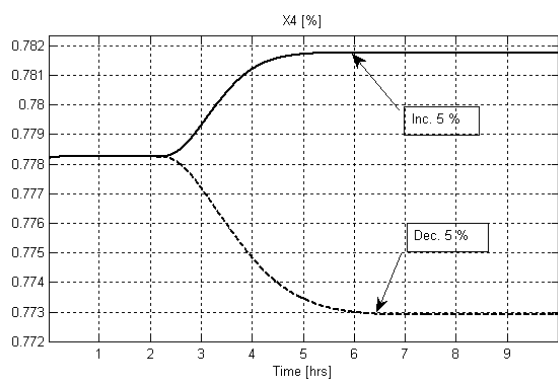

(b)

Fig. 6. Behavior of the concentration in the evaporator to a change of a step in the concentration of power (increase of $5 \%$ - decrease of $5 \%$ )

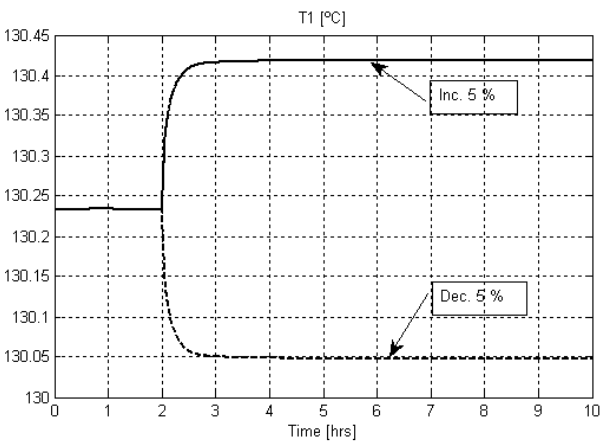

(a)

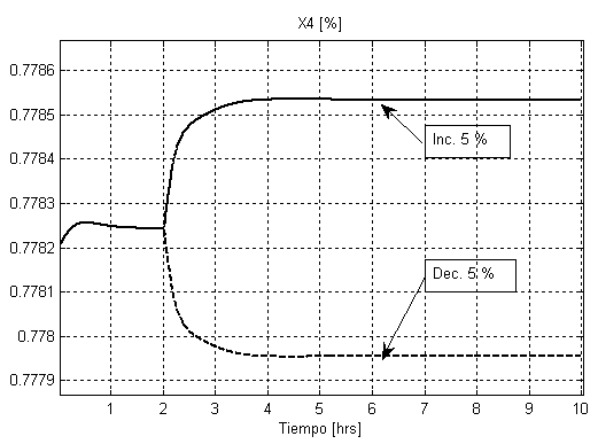

(b)

Fig. 7. Behavior of the concentration in the evaporator to a change of a step in the temperature of the input solution (5\% increase - decrease of $5 \%$ ) 


\subsection{Close loop}

Controlled system response for optimal regulator, whereas white noise disturbances, as well as step-like variation to the inlet concentration to 50 , and then a step 100 is added to the feed temperature at the entrance.

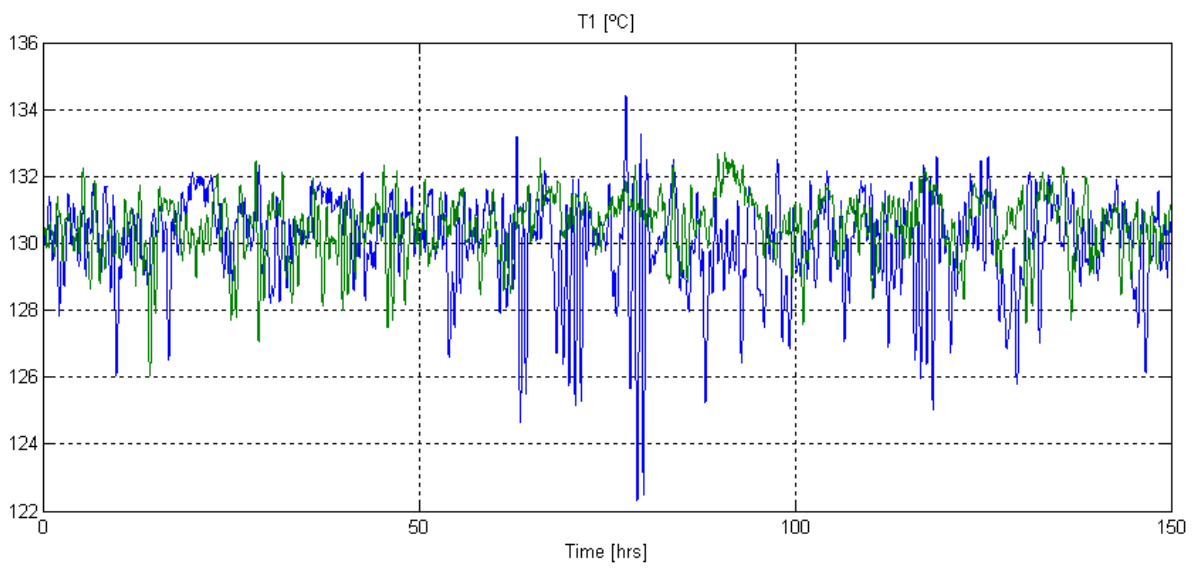

(a)

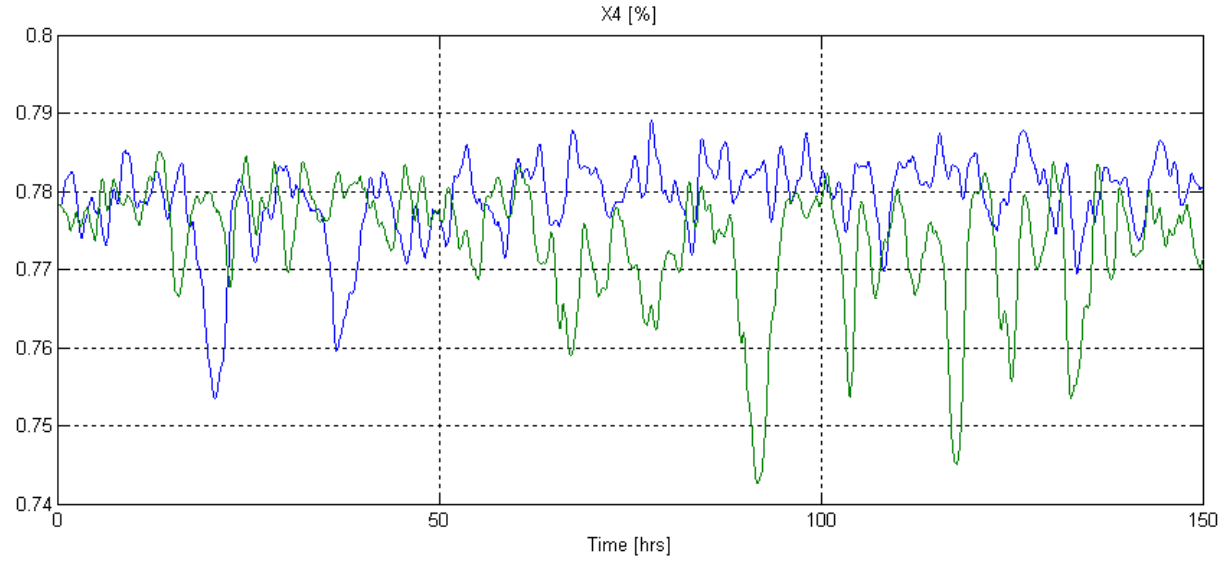

(b)

Fig. 8. Controlled system response to changes in the shocks in type of step and white noise (blue for changes of $+5 \%$ - green changes $-5 \%$ ) 


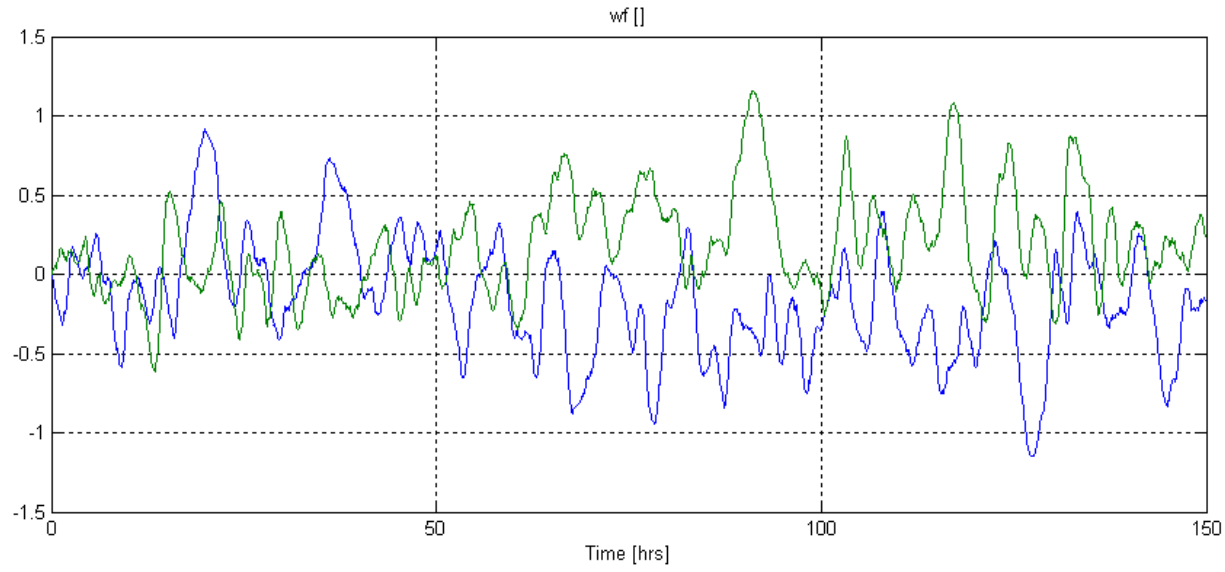

(a)

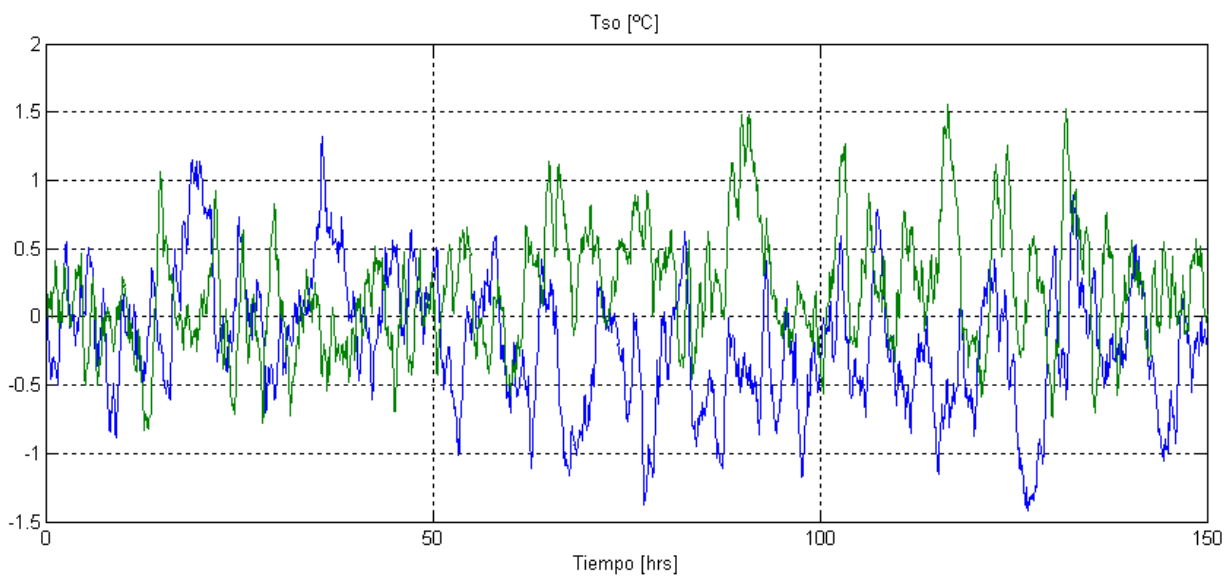

(b)

Fig. 9. Efforts to control the controlled system to changes in the shocks in type of step and white noise (blue for changes of $+5 \%$ - green changes $-5 \%$ ) 


\subsection{LQG- design}

Controlled system response for optimal regulator, whereas white noise disturbances, as well as like step variation of $5 \%$ for the inlet concentration to 50 and then to 100 adds a step is $5 \%$ of the feed temperature at the entrance.

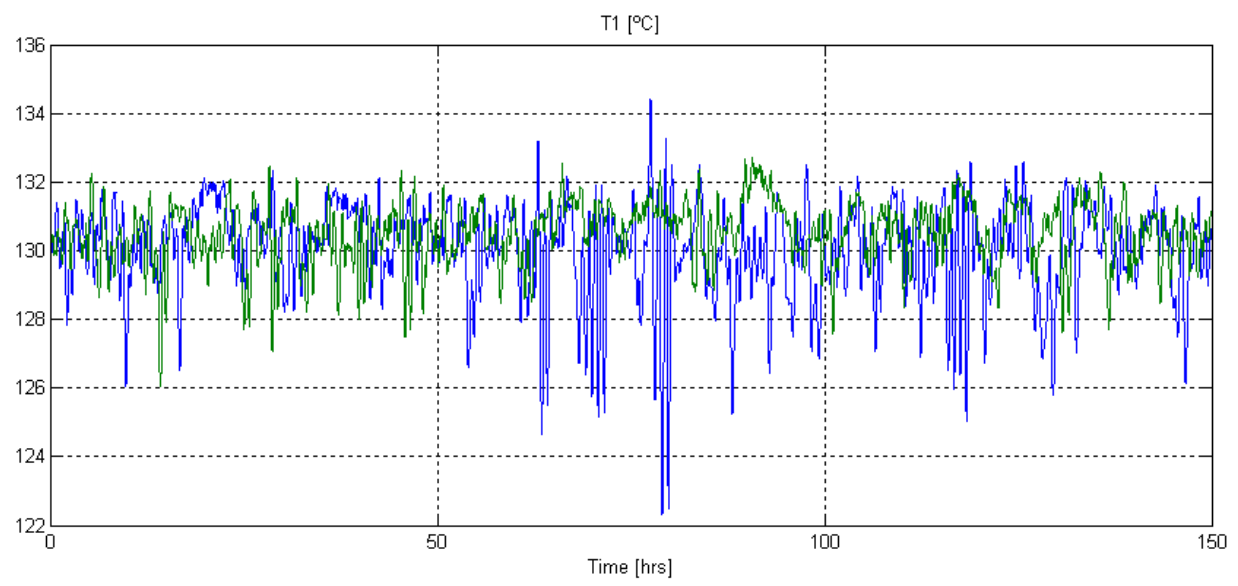

(a)

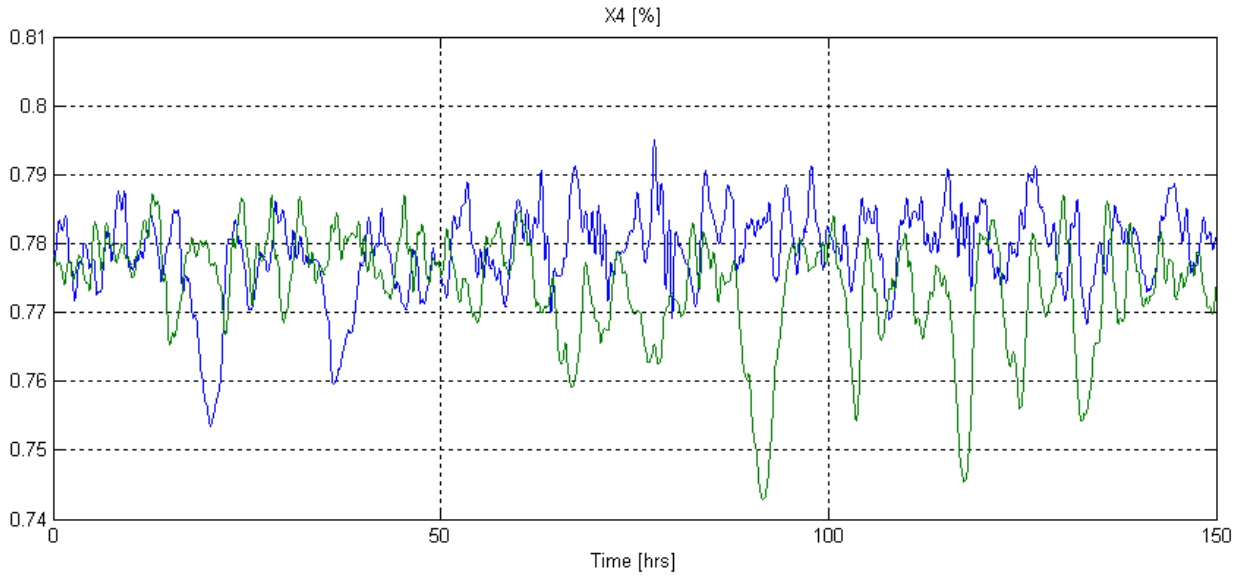

(b)

Fig. 10. LQG controlled system response to changes in the type shocks of step and white noise (blue for changes of $+5 \%$ - green changes $-5 \%$ ) 


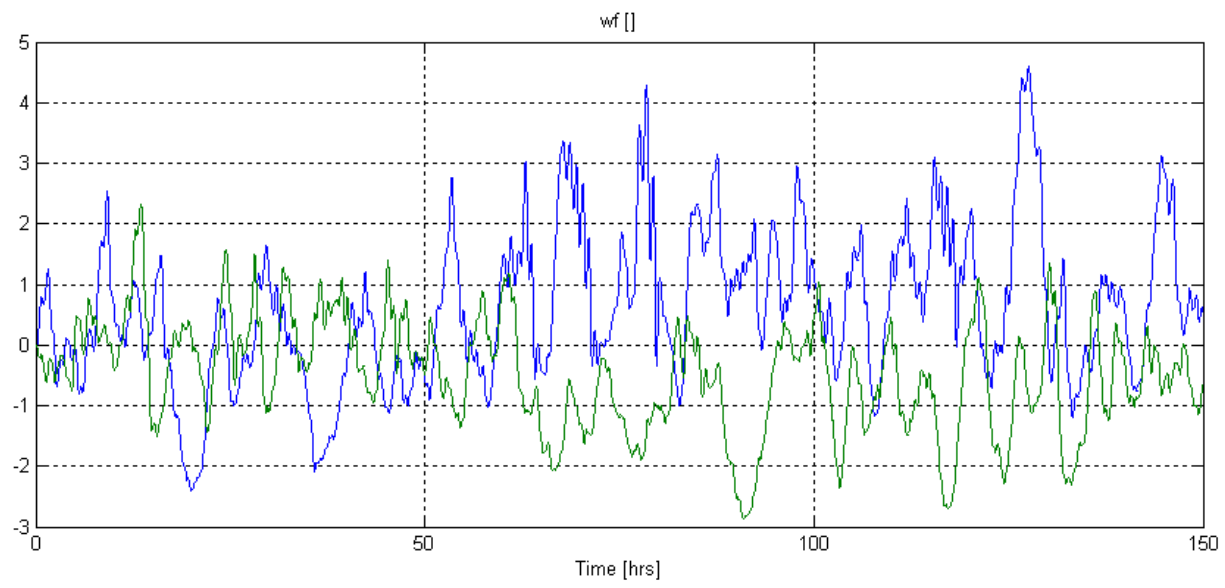

(a)

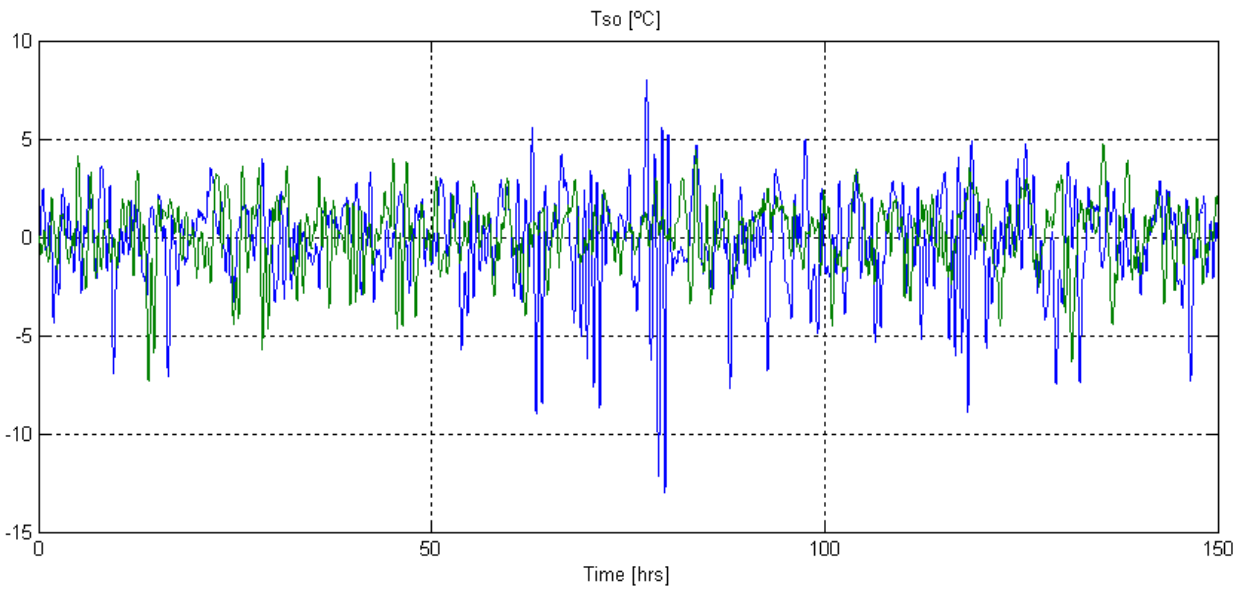

(b)

Fig. 11. Control efforts for the LQG-controlled system to changes in the type shocks of step and white noise (blue for changes of $+5 \%$ - green changes $-5 \%$ ) 


\subsection{LQG/LTR}

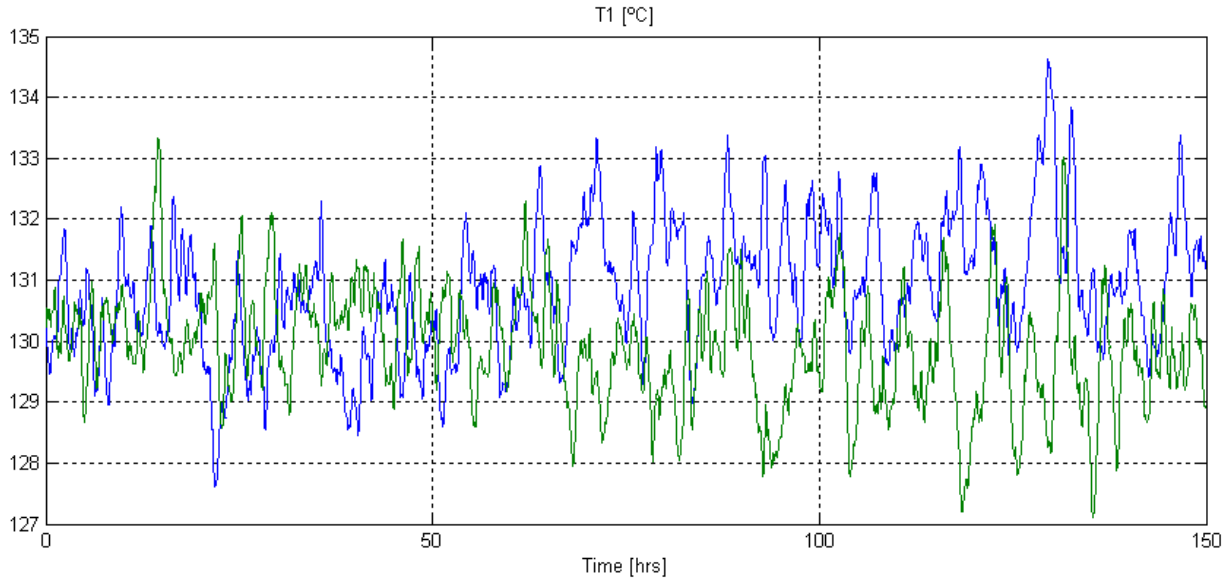

(a)

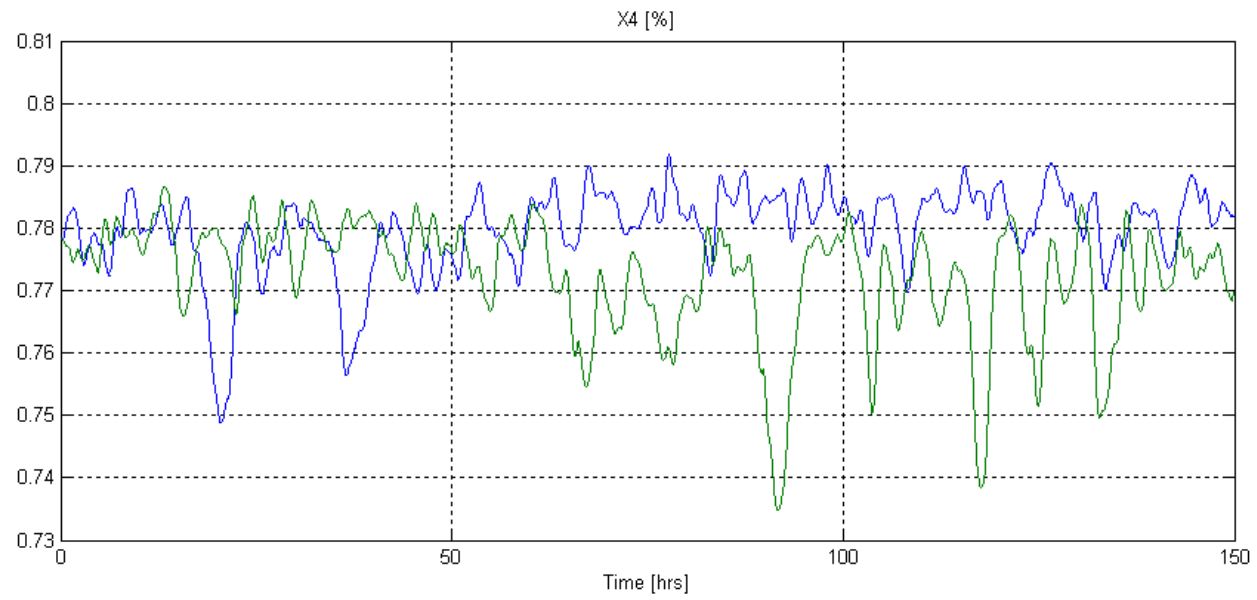

(b)

Fig. 12. Controlled system response LQG / LTR to changes in the type shocks of step and white noise (blue for changes of $+5 \%$ - green changes $-5 \%$ ) 


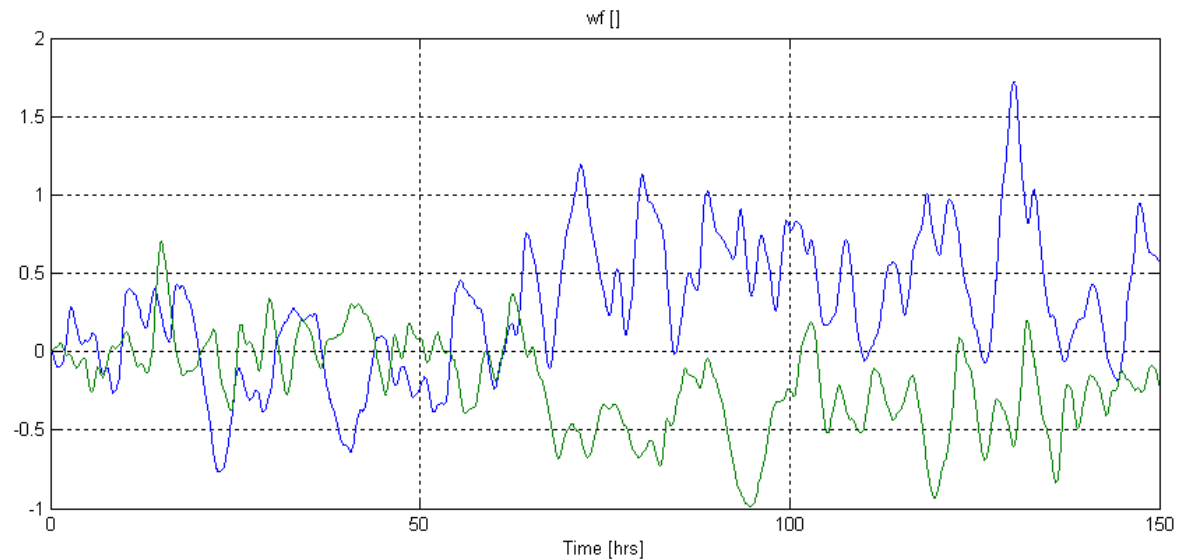

(a)

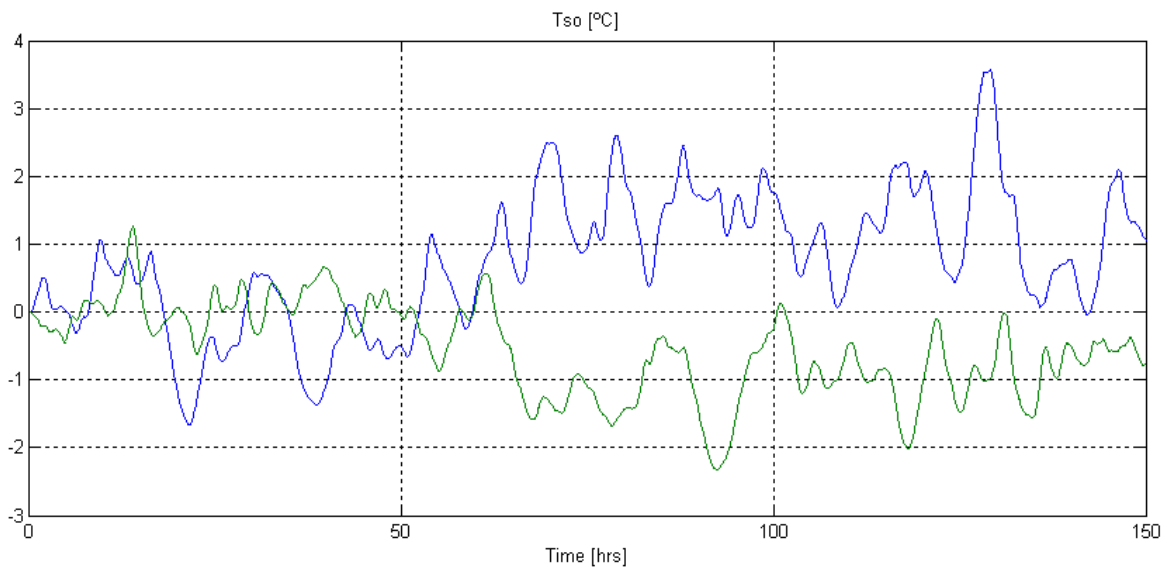

(b)

Fig. 13. Efforts to control the controlled system LQG / LTR to changes in the type shocks of step and white noise (blue for changes of $+5 \%$ - green changes $-5 \%$ )

\section{Conclusions}

Looking at the results presented in figures 4 to 7 , show that it is appropriate to consider as manipulated variables steam temperature and feed rate of the solution to concentrate, and as measurable disturbance and characteristic of the system to the concentration the solution concentrated and the inlet temperature of food. You can check the analysis of these figures that the evaporation process presents a complex dynamic, high delay, coupling between the variables, high nonlinearities.

From the results shown in figures 8 to 13 , on the behavior of the controlled system verifies that the design LQG/LTR has a better performance especially when control efforts are softer. Partly, it validates the robustness of the proposed control system, despite having analyzed only the rejection of disturbances, since these regulatory systems at the show a good response. 


\section{Acknowledgment}

The authors gratefully acknowledge the financial support of the "Universidad de La Frontera"- Chile DIUFRO DI07-0102, "Universidad Nacional de San Juan"- Argentina, Project FI-I900. They are also grateful for the cooperation of "Mostera Rio San Juan".

\section{References}

(Anderson, 1971) Anderson B.D.O., Moore J.B., Lineal Optimal Control Control. Prentice Hall. Engleewood Cliffs, N.J.

(AOAC, 1995) Official Methods of Analysis. Reference Tables Appendix C

(Armaou, 2002) Armaou A., Christofides P.D., “Dynamic Optimization of Dissipative PDE

Systems Using Nonlinear Order Reduction". Chemical Engineering Science 57 - 24, pp. 5083-5114.

(Aros, 1991) Aros N.H., Recuperación de la Transferencia del Lazo por Realimentación Parcial del Estado. M. Sc. Thesis. Universidad Técnica Federico Santa María, Chile.

(Barbieri, 1980) Barbieri, R., \& Rossi, N. "Propietà Fisiche dei Mosti d'uva Concentrati". Rivista de Viticol. e di Enologia. Conegliano, No 1, 10-18.

(Bayindirli, 1992) Bayindirli, L. "Mathematical Analysis Of Variation Of Density And Viscosity Of Apple Juice With Temperature And Concentration". Journal. Of Food Processing and Preservation (16), 23-28.

(Bode, 1945) Bode H.W., Network Analysis and Feedback Amplifier Design. Van Nostrand, New York.

(Camacho, 1999) Camacho E., Bordons F.C., Model Predictive Control. Springer-Verlag.

(Crapiste, 1988) Crapiste, G.H. and Lozano, J.E. “Effect Of Concentration And Pressure On

The Boiling Point Rise Of Apple Juice And Related Sugar Solutions". Journal Food Science. (53), 865-869

(Constela, 1989). Constenla D.T., Crapiste G.H. and Lozano J.E. “Thermophysical Properties Of Clarified Apple Juice As A Function Of Concentration And Temperature". Journal. Food Science.(54), 663-669.

(Di Leo, 1988) Di Leo, F. “Caratteristiche Fisico-chimiche dei Mosti Concentrati Rettificati. Valutazione gleucometrica". Vignevini, 15(1/2), 43-45.

(Doyle, 1979) Doyle J.C., Stein G., "Robustness with observers". IEEE Trans. on Auto. Control, Vol. AC-24, April.

(Enns, 1984) Enns D., Model reduction for control systems design. Ph. D. Thesis. Stanford University.

(El-Farra, 2003) El-Farra N.H., Armaou A., Christofides P.D., "Analysis and Control of Parabolic PDE Systems with Input Constraints". Automatica 39 - 4, pp. 715-725.

(Freudenberg, 1988) Freudenberg J., Looze D., Frequency Domain Properties of Scalar and Multivariable Feedback Systems. Springer Verlag, Berlín.

(Friedland, 1989) Friedland B., “On the properties of reduced-orden Kalman filters". IEEE Trans. on Auto. Control, Vol. AC-34, March.

(Ibarz, 1993) Ibarz, A., \& Ortiz, J. "Reología de Zumos de Melocotón". Alimentación, Equipos y Tecnología. Octubre, 81-86, Instituto Nacional de Vitivinicultura. Síntesis básica de estadística vitivinícola argentina, Mendoza. Varios números.

(Kam, 1999) Kam K.M., Tade M.O., "Case studies on the modelling and control of evaporation systems". XIX Interamerican Congress of Chemical Engineering COBEQ.

(Kam, 2000) Kam K.M., Tade M.O., "Simulated Nonlinear Control Studies of Five Effect Evaporator Models". Computers and Chemical Engineering, Vol. 23, pp. 1795 - 1810.

(Kaya, 2002) Kaya A., Belibagh K.B., "Rheology of solid Gaziantep Pekmez". Journal of Food Engineering, Vol. 54, pp. 221-226. 
(Middleton, 1990) Middleton R.H., Goodwin G.C., Digital Control and Estimation. A Unified Approach. Prentice Hall, Englewood Cliffs, N.J.

(Moressi, 1984). Moressi, M., \& Spinosi, M. "Engineering factors in the production of concentrated fruit juices, II, fluid physical properties of grapes". Journal of Food Technology, 5(19), 519-533.

(Niemann, 1995) Niemann H.H., Stoustrup J., Shafai B., Beale S., “LTR design of proportional-integral observers". Int. Journal Robust Nonlinear Control, pp. 671-693.

(Pandolfi, 1991) Pandolfi, C., Romano, E. \& Cerdán, A. Composición de los Mostos Concentrados Producidos en Mendoza y San Juan, Argentina. Ed. Agro Latino. Viticultura/Enología profesional 13, 65-74.

(Perry, 1997) Perry R., Perry's Chemical Engineers Handbook. 7TH Edition McGraw Hill.

(Pilati, 1998) Pilati, M. A., Rubio, L. A., Muñoz, E., Carullo, C. A., Chernikoff, R.E. \& Longhi, M. F. “Evaporadores Tubulares de Circulación Forzada: Consumo de Potencia en Distintas Configuraciones. III Jornadas de Investigación. FCAI - UNCuyo. Libro de Resúmenes, 40.

(Rao, 1984) Rao, M. A., Cooley, H. J., \& Vitali, A. A. “Flow Properties of Concentrated Juices at Low Temperatures. Food Technology, 3(38), 113-119.

(Rubio, 1998) Rubio, L. A., Muñoz, E., Carullo, C. A., Chernikoff, R. E., Pilati, M. A. \& Longhi, M. F. "Evaporadores Tubulares de Circulación Forzada: Capacidad de Calor Intercambiada en Distintas Configuraciones". III Jornadas de Investigación. FCAI - UNCuyo. Libro de Resúmenes, 40.

(Sáenz 1986) Sáenz, C., \& Costell, E. “Comportamiento Reológico de Productos de Limón, Influencia de la Temperatura y de la Concentración". Revista de Agroquímica y Tecnología de Alimentos, 4(26), 581-588.

(Saravacos, 1970) Saravacos, G. D. “Effect of Temperature on Viscosity of Fruit Juices and Purees". Journal of Food Science, (35), 122-125.

(Schwartz, 1986) Schwartz, M., \& Costell, E. "Influencia de la Temperatura en el Comportamiento Reológico del Azúcar de Uva (cv, Thompson Seedless)". Revista de Agroquímica y Tecnología de Alimentos, 3(26), 365-372.

(Stefanov, 2003) Stefanov Z.I., Hoo K.A., “A Distributed-Parameter Model of Black Liquor Falling Film Evaporators". Part I. Modeling of Single Plate. Industrial Engineering Chemical Research 42, 1925-1937.

(Stein, 1987) Stein G., Athans, M., “The LQG/LTR procedure for multivariable feedback control design". IEEE Trans. on Auto. Control, Vol. AC-32, February.

(Suarez, 2010) Suarez G.I., Ortiz O.A., Aballay P.M., Aros N.H., “Adaptive neural model predictive control for the grape juice concentration process". International Conference on Industrial Technology, IEEE-ICIT 2010, Chile.

(Turan, 1990) Turan L., Mingori D.L., Goodwin G.C., “Loop transfer recovery design biased and unbiased controllers". Technical Report EE9021, February.

(Wall, 1980) Wall J.E., Doyle J.C, Harvey C.A., "Tradeoffs in the design of multivariable feedback systems". Proc.18th Allerton Conf., October.

(Zang, 1990) Zang Z., Freudenberg J.S., “Loop transfer recovery for nonminimum phase plants". IEEE Trans. Automatic Control, Vol. 35, pp. 547-553.

(Zheng, 2002) Zheng D., Hoo K. A., “Low-Order Model Identification for Implementable Control Solutions of Distributed Parameter Systems". Computers and Chemical Engineering 26 7-8, pp. 1049-1076.

(Zuritz, 2005) Zuritz C.A., Muñoz E., Mathey H.H., Pérez E.H., Gascón A., Rubio L.A., Carullo C.A., Chemikoff R.E., Cabeza M.S., “Density, viscosity and soluble solid concentration and temperatures". Journal of Food Engineering, Vol. 71, pp. 143 - 149. 


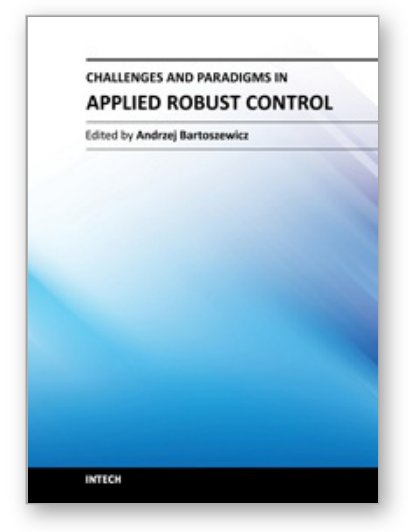

\author{
Challenges and Paradigms in Applied Robust Control \\ Edited by Prof. Andrzej Bartoszewicz
}

ISBN 978-953-307-338-5

Hard cover, 460 pages

Publisher InTech

Published online 16, November, 2011

Published in print edition November, 2011

The main objective of this book is to present important challenges and paradigms in the field of applied robust control design and implementation. Book contains a broad range of well worked out, recent application studies which include but are not limited to $\mathrm{H}$-infinity, sliding mode, robust PID and fault tolerant based control systems. The contributions enrich the current state of the art, and encourage new applications of robust control techniques in various engineering and non-engineering systems.

\title{
How to reference
}

In order to correctly reference this scholarly work, feel free to copy and paste the following:

Nelson Aros Oñate and Graciela Suarez Segali (2011). Loop Transfer Recovery for the Grape Juice Concentration Process, Challenges and Paradigms in Applied Robust Control, Prof. Andrzej Bartoszewicz (Ed.), ISBN: 978-953-307-338-5, InTech, Available from: http://www.intechopen.com/books/challenges-andparadigms-in-applied-robust-control/loop-transfer-recovery-for-the-grape-juice-concentration-process

\section{INTECH}

open science | open minds

\author{
InTech Europe \\ University Campus STeP Ri \\ Slavka Krautzeka 83/A \\ 51000 Rijeka, Croatia \\ Phone: +385 (51) 770447 \\ Fax: +385 (51) 686166 \\ www.intechopen.com
}

\author{
InTech China \\ Unit 405, Office Block, Hotel Equatorial Shanghai \\ No.65, Yan An Road (West), Shanghai, 200040, China \\ 中国上海市延安西路65号上海国际贵都大饭店办公楼 405 单元 \\ Phone: +86-21-62489820 \\ Fax: $+86-21-62489821$
}


(C) 2011 The Author(s). Licensee IntechOpen. This is an open access article distributed under the terms of the Creative Commons Attribution 3.0 License, which permits unrestricted use, distribution, and reproduction in any medium, provided the original work is properly cited. 